\title{
IS THE LONGITUDINAL PROFILE OF STORGLACIÄREN, NORTHERN SWEDEN, IN BALANCE WITH THE PRESENT CLIMATE?
}

\author{
By Per HolmLund \\ (Department of Physical Geography, University of Stockholm, S-106 91 Stockholm, Sweden)
}

ABstract. The main perturbation in the mass balance of Storglaciären during the twentieth century was caused by a sudden $1{ }^{\circ} \mathrm{C}$ increase in the summer mean temperature around 1910. Later perturbations of the climate have been of minor importance in relation to the mass balance. Annual field surveys suggest that the mass budget on Storglaciären has been in near balance for the last 15 years. Because of this major step-like change, we can establish the validity of theoretical models giving response times for Storglaciären of the order of 50 years. According to these models, Storglaciären could by now have reached a profile in balance with the present climate. To study this problem, the emergence velocity was calculated and compared with the net balance. The result shows that the emergence velocity either balances or exceeds the net balance for the entire tongue except for the lowermost part, where it decreases to about half of the net balance. A slight further recession of the front position would thus be expected with today's climate.

Calculated balance velocities also suggest that most of the present profile is close to a steady-state profile, if the mean annual sliding velocity is about $50 \%$ of the surface velocity. Lower sliding velocities would imply a thickening of the tongue and a thinning of the accumulation area during years of balanced mass budget.

\section{INTRODUCTION}

The purpose of this paper is to estimate whether or not the profile of Storglaciären is in balance with the present climate. The basic material for the study is the 42 year record of the mass balance of Storglaciären.

Prior to 1945, when the mass-balance study was initiated, only frontal position data were available. These show that the glacier reached a maximum forward position around 1910, followed by a mass loss and a retreat of the front caused by a $1{ }^{\circ} \mathrm{C}$ increase in summer mean temperature (Holmlund, 1987). Since the mid-1970s, Storglaciären has had a near-balanced budget and the recession velocity of the front has now (in the 1980s) declined to almost zero (Fig. 1). A study of maps shows that the glacier became thinner at the tongue but thicker in its upper accumulation area between 1959 and 1980 (Holmlund, 1987, fig. 5). This paper will therefore deal mainly with the lower part of the glacier, in an attempt to estimate the state of today's profile. As discussed below,

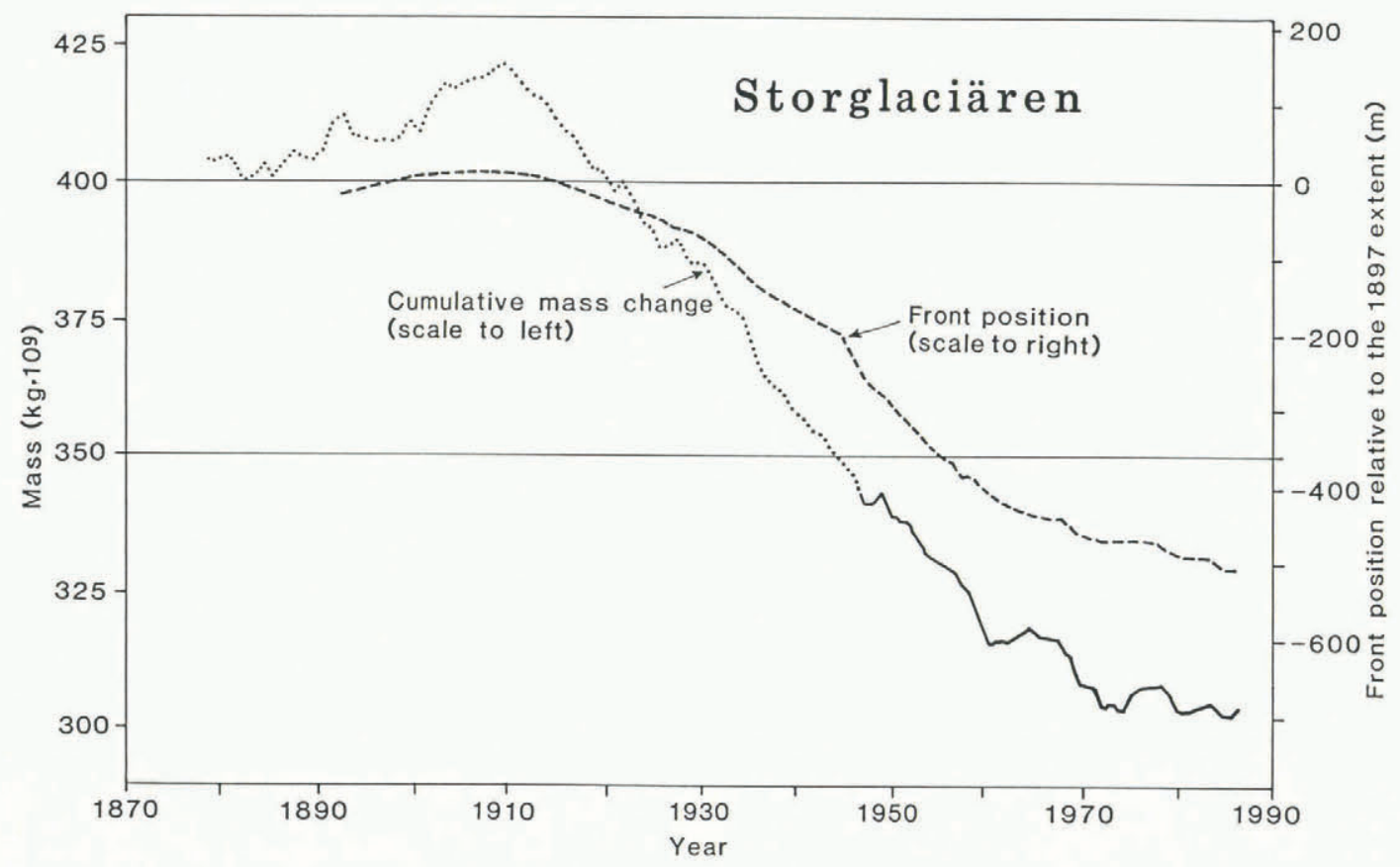

Fig. 1. Cumulative mass change of Storglaciären, 1878-1987. The dotted line indicates calculated mass balance based on regression analysis, using temperature data from the meteorological station in Karesuando, northern Sweden (Holmlund, 1987). The solid line is the mass-balance data measured in the field. The dashed line shows change $(m)$ in the frontal position of the glacier relative to the first survey in 1897 (Schytt, 1979). 
estimates of the response time for Storglaciären show that it is probably of the order of 50 years (Nye, 1965a; Jóhannesson and others, in press).

Two different approaches, both based on the mass-balance and ice-velocity data have been used. First, the mass-balance data for the last 15 years are used to calculate balance velocities for comparison with velocity measurements made in the field between 1982 and 1985 (Hooke and others, 1986). These same data are then also used in a comparison between net mass balance and emergence velocity at different locations on the glacier surface.

\section{PHYSICAL SETTING}

Storglaciären is situated in the Kebnekaise mountain massif in northern Sweden (lat. $67^{\circ} 55^{\prime} \mathrm{N}$., long. $18^{\circ} 35^{\prime} \mathrm{E}$ ). It has been described by Schytt (1959), Østrem and others (1973), Hooke and others (1983b), and Holmlund (1987). It can be classified as a temperate valley glacier with a divided accumulation area (Fig. 2) and with a perennially cold $\left(<0^{\circ} \mathrm{C}\right)$ surface layer in its lower parts (Schytt, 1968; Østrem and others 1973; Hooke and others, 1983a).

\section{RESPONSE TIME}

In theory, the response time of a glacier is of ten defined as the time required for a glacier to change its shape or extension from one non-steady state condition approximately two-thirds (more specifically $1-(1 / \mathrm{e})$ ) of the way to a new steady state. Minor adjustments will therefore occur even after a response has been completed, in the theoretical meaning of the word. Nye (1965a, fig. 4a, p. 600) has used a kinematic wave theory to calculate the response time for a positive change in mass balance and obtained 50-60 years for Storglaciären. In the present paper, the calculated value for the response time of a glacier to a unit pulse is also assumed to be valid for a change described by a step function. By a simplification of this theory, also suggested by Nye (1960) (where the effect of diffusion is neglected), the response time (tr) may be estimated from the longitudinal strain-rate, $\dot{\varepsilon}$, where tr $\sim 1 / 3 \dot{\varepsilon}_{x x}$ ). This gives a slightly lower value for the response time. The velocity at the equilibrium line is of the order of $20 \mathrm{~m} /$ year, while the velocity at the front, which is situated about $2 \mathrm{~km}$ down-glacier, is zero. The average longitudinal strain-rate is therefore about -0.01 resulting in a response time of 33 years. Jóhannesson and others (in press) used a "volume time-scale" approach, defined as "how long it would take to add or lose a given volume of ice", after a perturbation in the mass balance has taken place. In the most simplified case, that of a temperate glacier resting on a flat bed, the response time is only dependent on the net ablation at its terminus and a scale factor for the thickness of the glacier. A complex bottom topography makes the determination of a suitable thickness scale more difficult. Using their model, the response time for Storglaciären also works out at about 50 years, in good agreement with Nye's (1965a) estimate.

Even though the climate seems to have behaved in an almost ideal way, a detailed study exposes small perturbations during the period after 1910. As there is an 11 year cycle in the mass-balance data (Holmlund, 1987, fig. 2), the sun-spot cycle seems to influence the climate. These particular perturbations may also have a slight influence on the time required for the glacier to adopt a steady-state profile.

The bottom topography of Storglaciären is rough, which is of significance in the Johannesson and others (in press) model, as it may lead to difficulties in determining the thickness scale required for the estimate of the volume time-scale. In addition, the glacier front has recently become steeper, leading to an increased accumulation of snow at the front because of the lee effect. This delays the formation of a steady-state profile in the lowermost part of the glacier, because no net ablation occurs there except during very warm summers. Another complicating factor is that the glacier was probably not in a steady state in the years just before the climatic change in 1910 (Holmlund, 1987).

\section{NET MASS BALANCE}

Mass-balance measurements have been carried out on Storglaciären since 1946 when the first winter balance was determined (Schytt, 1947). The methodology of the field measurements has been described in detail by Holmlund (1987). The mean specific annual net loss between 1945-46 and 1986-87 was $0.36 \mathrm{~m}$ (Holmlund, 1987, fig. 2). However, the corresponding value for the last 15 years is zero $(-0.003 \mathrm{~m})$, though the period includes extreme values such as $-1.27 \mathrm{~m}$ (1980) and $+1.17 \mathrm{~m}$ (1975) (Fig. 3). According to these measurements, the glacier seems to be in a near balanced state with the present climate.

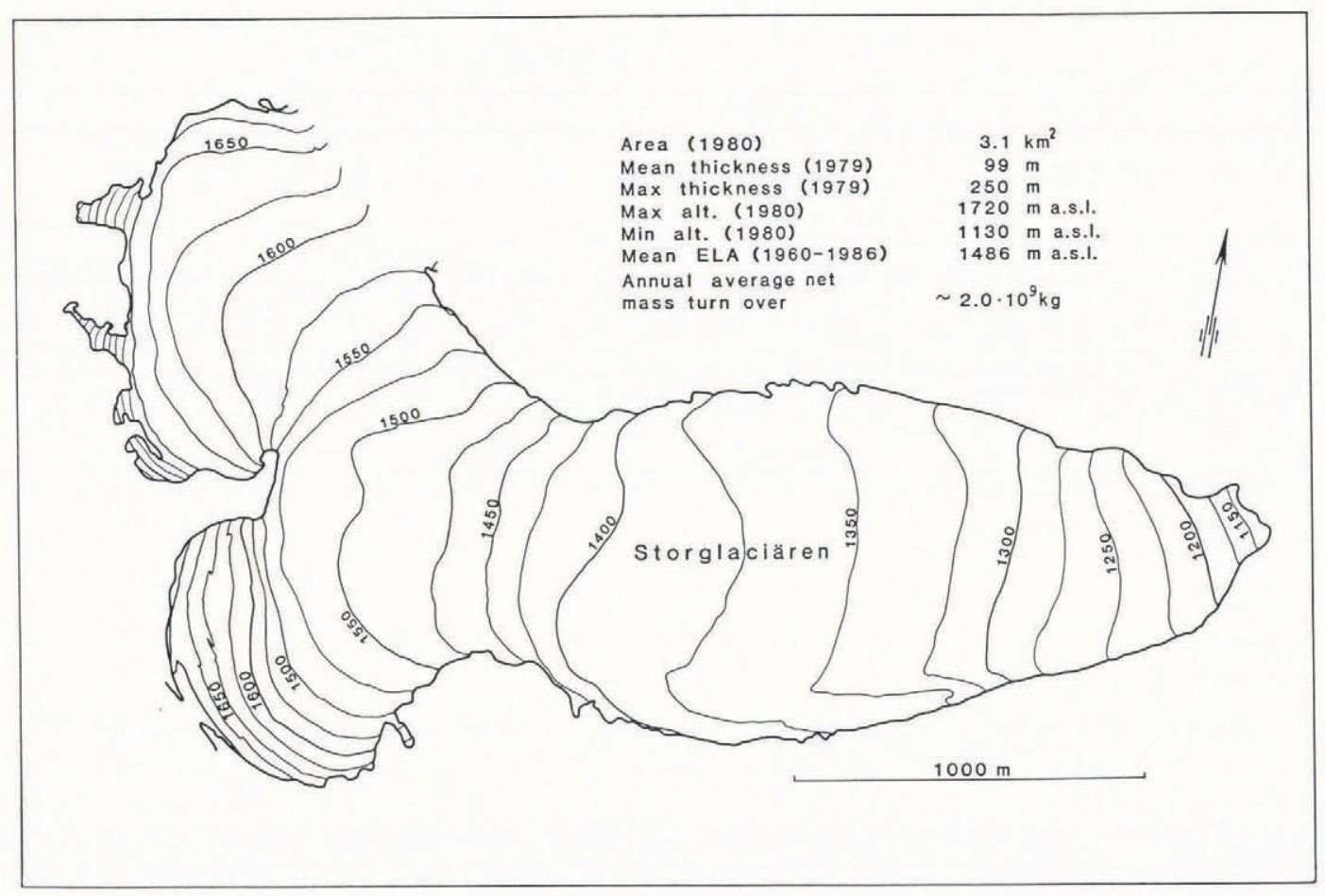

Fig. 2. Map of Storglaciären based on aerial photographs taken in 1980. 


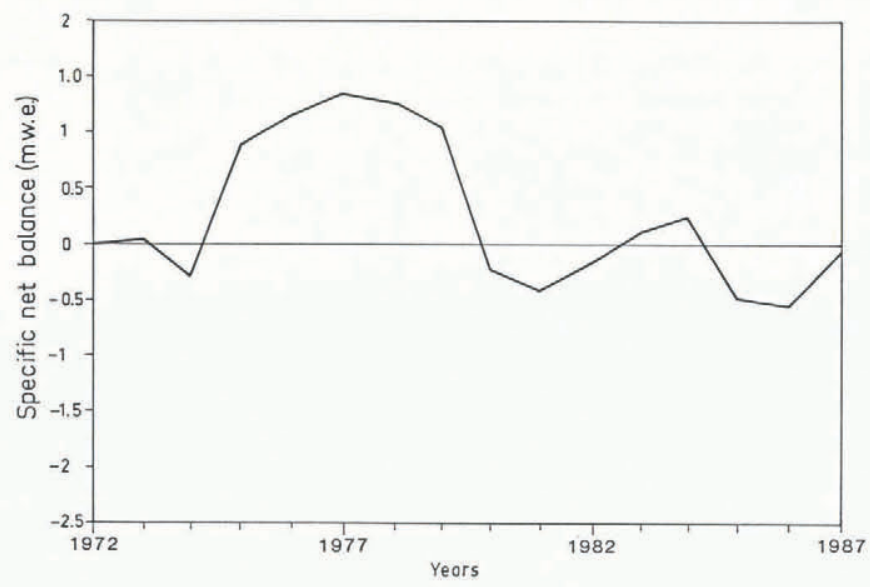

Fig. 3. The cumulative net mass balance of Storglaciären between 1972 and 1987, expressed in specific water equivalent $(m)$.

\section{EMERGENCE VELOCITY}

The emergence velocity is the specific amount of ice that is transported up to the glacier surface per year. In a steady state, it equals the mean ablation rate. The corresponding submergence velocity is the downward velocity in the accumulation area. In a steady state, this submergence velocity balances mean net accumulation. The emergence velocity $(V)$ is calculated by subtracting the surveyed vertical velocity $(\mathrm{d} Y)$ from the tangent of the surface slope $(\alpha)$, multiplied by the horizontal velocity $(\mathrm{d} X)$. Thus,

$$
V=\mathrm{d} X \tan \alpha-\mathrm{d} Y
$$

(Paterson, 1981, p. 61). Figure 4a shows the emergence

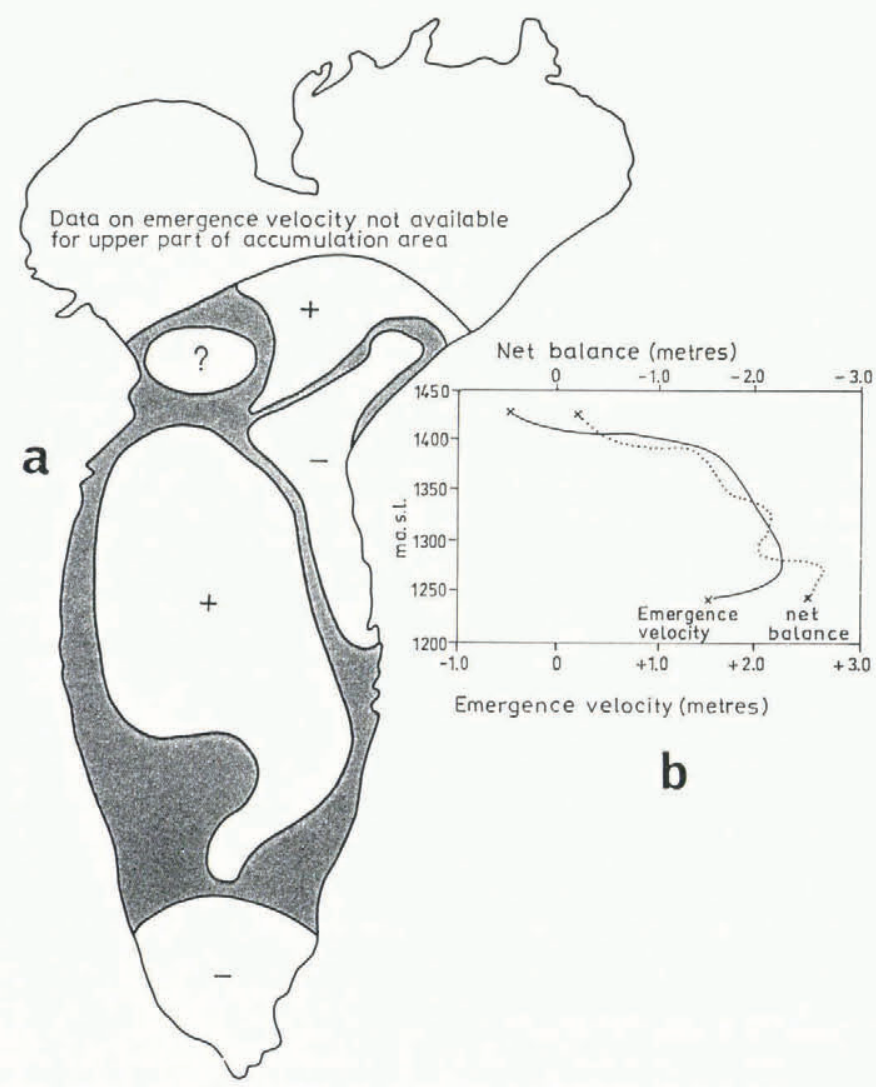

Fig. 4.a. Map showing the areal extent of areas that are changing in elevation, according to these calculations. Within the shaded area, change is $<|0.2 \mathrm{~m} / \mathrm{a}|$.

$b$. Emergence velocity (solid line) and net balance (dotted line) in $m /$ year as a function of the altitude ( $m$ a.s.l.). velocity minus the net mass balance, and Figure $4 \mathrm{~b}$ shows the emergence velocity and average net ablation rate for the years 1983, 1984, and 1986 adjusted to one reconstructed balance year, as a function of the altitude. (The mean annual net balance for these 3 years was $+0.11 \mathrm{~m}$ w.e. This value was subtracted from the measured net ablation at each point studied and the net ablation adjusted to a balance year. The net-balance gradient for these years deviates only a little from the mean for the last 15 years.)

The values for both the net balance and the emergence velocity show large local variations. Figure $4 \mathrm{~b}$ can therefore only show the situation along one specific profile. However, the curves agree fairly well except for the lowermost part of the glacier, where they diverge significantly. This implies that most of the tongue, except for that part near the terminus, has a positive balance or is in balance with today's climate. The terminus will recede a little more until the slope of the front allows ice flow sufficiently large to balance the net ablation.

\section{BALANCE VELOCITY}

Another way of evaluating the state of a glacier is to calculate the balance velocity, based on mass-balance measurements, and to compare these values with velocity measurements made in the field. The balance velocity is calculated here by using the last 15 budget years, for which the net mass balance was close to zero.

The ice-velocity measurements used for comparison were made in the field between 1982 and 1985 on a series of 32 stakes distributed over the glacier (Hooke and others, 1986; personal communication from R. LeB. Hooke, November 1986). To calculate the balance velocity, the surface area up-glacier from the locations of movement measurements were obtained, and the mass gain or loss from this area during one balance year was calculated from the net-balance data (Table I). This mass (Table II, col. 2) was then divided by the cross-sectional area normal to the flow at the location of the velocity measurements (Table II, col. 3) to obtain an estimate of the balance velocity (Table II, col. 4). The bottom topography was taken from a map based on radio echo-soundings (Björnsson, 1981).

The velocity measurements (Table II, col. 5) were generally made close to the center line, where the velocity is significantly higher than at the margin. Therefore, they are not representative of the average velocity through the cross-section. This problem is approached here first by assuming no basal sliding, and then by making an assumption about the amount of basal sliding, First, Nye's $(1965 \mathrm{~b}$, p. 677) results are used to estimate the mean velocity over the cross-section (approximated as parabolic) from the measured surface velocities. The ratio between the average velocity through a cross-section and the surface velocity at the center line $\left(\bar{u} / u_{\mathrm{c}}\right)$ (Table II, col. 6) is calculated, and then the average ice velocity at the cross-section is obtained (Table II, col. 7) by multiplying the surveyed surface velocities by this ratio. This value of $\bar{u} / u_{\mathrm{c}}$ is known to be low, because basal sliding occurs. Col. 7 is therefore a minimum value of $\bar{u}$.

The minimum value of the contribution of basal sliding, using the difference in velocity between summer and winter, and assuming no sliding during the winter, has been estimated to be $10 \pm 5 \%$ (Holmlund, 1986). Adapting this value to these estimates increases the numbers in col. 7 of Table II by $5-7 \%$, which is insignificant.

If all movement were a result of basal sliding, $\bar{u} / u_{c}$ would equal 1 , and the velocity would be uniform all through the cross-section, $u$ s would then equal $\bar{u}$ and this would be a maximum value (Fig. 5, curve (a)). However, velocities are known to decrease towards the margin (Hooke and others, 1983b), indicating a $\bar{u} / u_{\mathrm{c}}$ ratio less than 1 . On the other hand, inclinometry measurements in bore holes on the tongue of the glacier show that sliding velocities locally reach $80-90 \%$ of the surface velocity in the summer (paper in preparation by V. Pohjola and L. LeB. Hooke), and in one place even exceed the surface velocity (at about $1340 \mathrm{~m}$ a.s.l; see Fig. 5) (Hooke and others, 1987). Thus, this ratio could approach 1 . Since field evidence for a more refined estimate of the average basal sliding is lacking, I arbitrarily chose the ratio $\bar{u} / u_{\mathrm{c}}=0.85$, which corresponds to about $50 \%$ sliding (Fig. 5). 
TABLE I. MASS-BALANCE DATA USED TO CALCULATE BALANCE VELOCITY. THE FIGURES ARE EXPRESSED AS NET BALANCE IN THOUSANDS OF CUBIC METRES FOR DIFFERENT ALTITUDE RANGES IN $\mathrm{m}$ a.s.I.

$\begin{array}{ccc}\begin{array}{c}\text { Interval } \\ \mathrm{m} \text { a.s.1. }\end{array} & \begin{array}{c}\text { Mean annual mass } \\ 1973-87\end{array} \\ & \text { w.e. } \times 10^{6} \mathrm{~m}^{3} & \mathrm{~m} \\ 1720-1560 & 1258 & (+1.53) \\ 1560-1460 & 348 & (+0.54) \\ 1460-1400 & -60 & (-0.27) \\ 1400-1380 & -196 & (-0.91) \\ 1380-1360 & -271 & (-1.00) \\ 1360-1340 & -301 & (-1.22) \\ 1340-1320 & -187 & (-1.28) \\ 1320-1300 & -99 & (-1.15) \\ 1300-1280 & -111 & (-1.59) \\ 1280-1140 & -397 & (-1.31) \\ 1320-1310 & -50 & (-1.15) \\ 1300-1290 & -56 & (-1.59)\end{array}$

TABLE II. DATA USED TO CALCULATE BALANCE VELOCITIES

(1)

\begin{tabular}{|c|c|c|}
\hline Level & Flux & $\begin{array}{c}\text { Cross-sectional } \\
\text { area }\end{array}$ \\
\hline m a.s.l. & $\mathrm{m}^{3} \times 10^{5}$ & $\mathrm{~m}^{2} \times 10^{5}$ \\
\hline 1460 & 17.8 & 0.75 \\
\hline 1400 & 17.2 & 1.27 \\
\hline 1380 & 15.0 & 1.32 \\
\hline 1360 & 12.0 & 1.11 \\
\hline 1337 & 8.6 & 0.63 \\
\hline 1312 & 6.0 & 0.52 \\
\hline 1292 & 4.9 & 0.48 \\
\hline
\end{tabular}

(4)

Calculated
$u$
$\mathrm{~m} /$ year

23.7

13.5

11.4

10.8

13.7

11.5

10.2
(5)

Measured $u_{x x}$
on center line $\mathrm{m} /$ year

28.5
17.7
13.8
12.7
13.6
13.0
11.5

17.7

13.8

13.6

11.5

$\bar{u} / u_{\mathrm{c}}$
(Nye, $1965 \mathrm{a})$

0.65
0.66
0.63
0.62
0.59
0.61
0.61

$u_{\text {av }}$ $\mathrm{m} /$ year

18.5

11.6

8.7

7.9

8.0

7.9

7.0

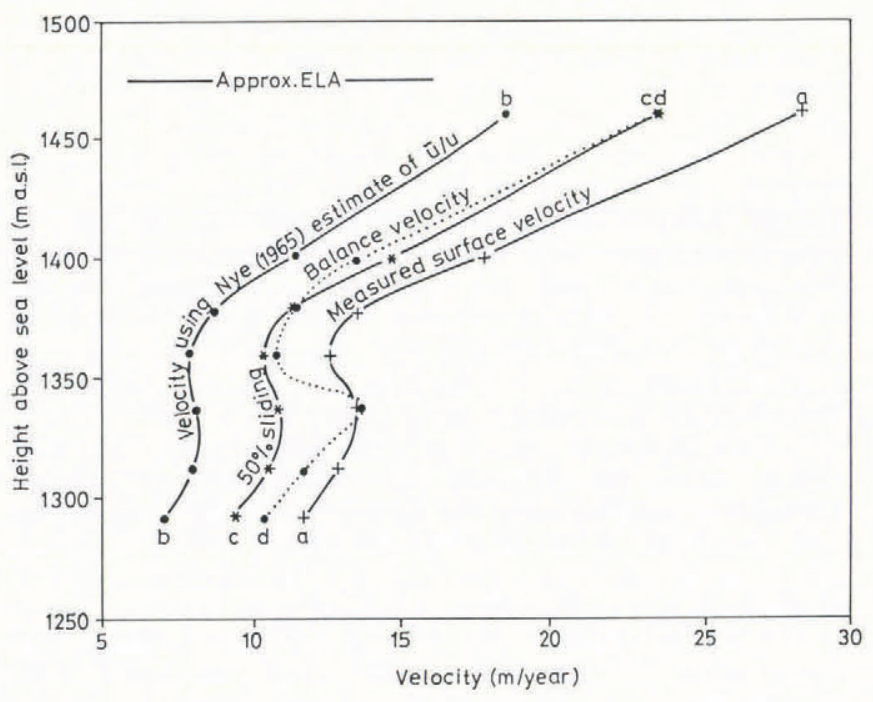

Fig. 5. Calculated balance velocity, surveyed surface velocity, and various estimates of mean velocity in a cross-section plotted as functions of the altitude. a. Measured surface velocity along the center line. $b$. Curve ( $a$ ) reduced by assuming a parabolic cross-section and no basal sliding, to obtain an estimate of the average velocity over a transverse profile $(N y e, 1965 b)$. c. The same, but allowing for 50\% sliding (dotted line). $d$. Calculated balance velocity. The large bulge on the dotted line at about $1340 \mathrm{~m}$ a.s.l. coincides with the extremely high sliding rate measured by inclinometry in a bore hole at this site (Hooke and others, 1987).

\section{CONCLUSIONS}

The emergence velocity seems to balance the net ablation on the tongue of Storglaciären, except for the lowermost part of the tongue where it is only half of that required. Therefore, most of Storglaciären is probably close to being in equilibrium with today's climate. The front, however, will recede slightly before the entire profile is in equilibrium with the climate, if the balanced mass budget persists.

The balance-velocity study shows that the surveyed velocity is comparable to the balance velocity above $1375 \mathrm{~m}$ (Fig. 5), if the sliding velocity is $50 \%$ of the surface velocity. However, the real sliding rate is not well known, as bore-hole deformation measurements are, so far, too few to draw any general conclusions for the entire glacier tongue and over a full year. If the sliding rate is less than $50 \%$ of the surface velocity, the glacier tongue may increase in thickness.

Today's glacier therefore appears to be approaching a steady state but some minor mass redistribution is expected during the next few years. However, in terms of the theoretical response time, the glacier is now close enough to a steady state to conclude that, in general, the theory is in reasonable agreement with the field data.

\section{ACKNOWLEDGEMENTS}

I am very grateful to Professor R. LeB. Hooke for his critical comments on the content of this paper. He also provided the idea for Figure 5. Thanks are due to $T$. Jóhannesson who made helpful comments on the manuscript. Finally, I should like to thank E. Granbom who drew the illustrations. 


\section{REFERENCES}

Björnsson, H. 1981. Radio-echo sounding maps of Storglaciären, Isfallsglaciären and Rabots glaciär, northern Sweden. Geogr. Ann., 63A(3-4), 225-231.

Holmlund, P. 1986. Mikkaglaciären: bed topography and response to 20th century climate change. Geogr. Ann., 68A(4), 291-302.

Holmlund, P. 1987. Mass balance of Storglaciären during the 20th century. Geogr. Ann., 69A(3-4), 439-447.

Hooke, R. LeB., J.E. Gould, and J. Brzozowski. 1983a. Near-surface temperatures near and below the equilibrium line on polar and subpolar glaciers. $Z$. Gletscherkd. Glazialgeol., 19(1), 1-25.

Hooke, R. LeB., J. Brzozowski, and C. Bronge. 1983 b. Seasonal variations in surface velocity, Storglaciären, Sweden. Geogr. Ann., 65A(3-4), 263-277.

Hooke, R. LeB., P. Holmlund, P. Calla, and M. Nilsson. 1986. Seasonal and spatial variations in surface velocity, Storglaciären, Sweden. Eidg. Tech. Hochschule, Zürich. Versuchsanst. Wasserbau, Hydrol. Glaziol. Mitt. 90, 59-60.

Hooke, R. LeB., P. Holmlund, and N.R. Iverson. 1987. Extrusion flow demonstrated by bore-hole deformation measurements over a riegel, Storglaciären, Sweden. J. Glaciol., 33(113), 72-78.

Jóhannesson, T., C.F. Raymond, and E.D. Waddington. In press. A simple method for determining the response time of glaciers. In Symposium on Glacier Fluctuations and Climatic Change. Amsterdam, I-5 June 1987. Proceedings.

Nye, J.F. 1960. The response of glaciers and ice-sheets to seasonal and climatic changes. Proc. R. Soc. London, Ser. A, 256(1287), 559-584.

Nye, J.F. 1965a. A numerical method of inferring the budget history of a glacier from its advance and retreat. J. Glaciol., 5(41), 589-607.

Nye, J.F. 1965b. The flow of a glacier in a channel of rectangular, elliptic or parabolic cross-section. J. Glaciol. 5(41), 661-690.

Østrem, G., N. Haakensen, and O. Melander. 1973. Atlas over breer i Nord-Skandinavia. Stockholms Univ. Naturgeogr. Inst. Medd. 46.

Paterson, W.S.B. 1981. The physics of glaciers. Second edition. Oxford, etc., Pergamon Press.

Schytt, V. 1947. Glaciologiska arbeten i Kebnekajse. Ymer, 67(1), 118-142.

Schytt, V. 1959. The glaciers of the Kebnekajse-massif. Geogr. Ann., 41(4), 213-227.

Schytt, V. 1968. Notes on glaciological activities in Kebnekaise, Sweden during 1966 and 1967. Geogr. Ann., 50A(2), $111-120$.

Schytt, V. 1979. Tarfala and its research activities. Stockholm, University of Stockholm. Department of Physical Geography. 